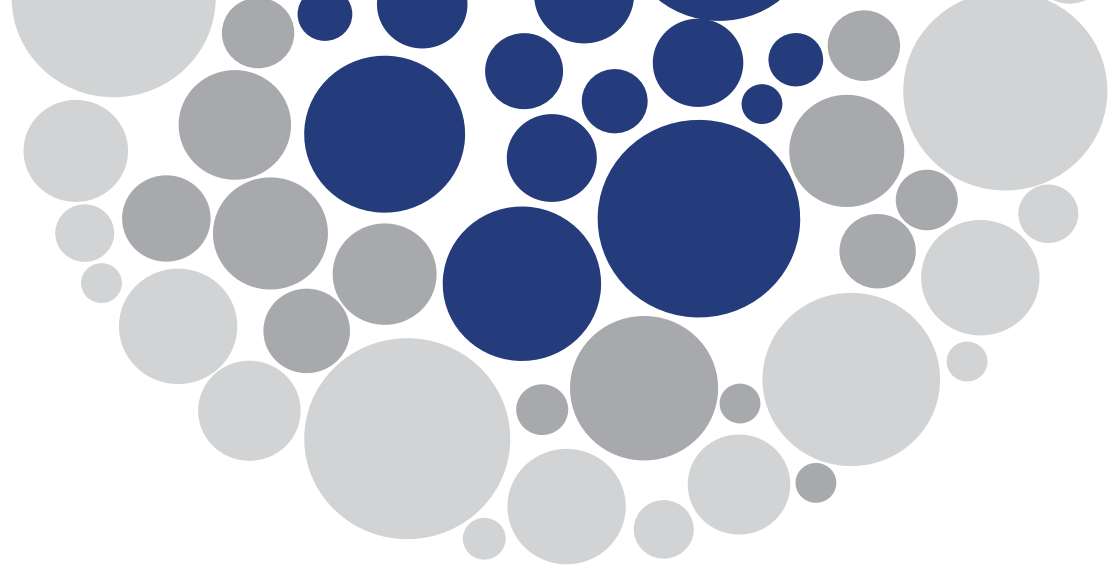

\title{
Ensaio sobre a precarização do trabalho e a crise urbana em tempos de pandemia
}

\author{
Tatiana Tramontani Ramos a \\ a Universidade Federal Fluminense; Departamento de Geografia da UFF/Campos; Programa de Pós-Graduação em Geografia \\ da UFF/CAMPOS, Campos dos Goytacazes (RJ), Brasil. E-mail: tatiana_tramontani@id.uff.br
}

\section{Introdução}

O período atual, por diferentes motivos e intensidades, ficará marcado como um período excepcional da história mundial, e um dos objetos que dá relevo e profundidade muito preocupante à pandemia da Covid-19 é a questão do mundo do trabalho.

Falar de trabalho com questão é tratá-lo como complexo, isto é, multifacetado e diversamente justificado. O trabalho é dotado de densidade histórica, social e cultural, além de conceitualmente definido e interpretado por muitos pensadores ao logo do tempo ${ }^{1}$. Não é nosso objetivo discutir o conceito de trabalho neste texto, mas partimos de uma delimitação materialista e histórica que o percebe como a principal referência na composição do valor e, consequentemente, uma categoria sine qua non do modo de produção capitalista.

Se o trabalho é central em nossa atual condição de existência, não é dispensável ressaltar que ele acompanha as próprias transformações das sociedades, adaptando-se

\footnotetext{
${ }^{1}$ Desde os clássicos Karl Marx e Friedrich Engels, passando por marxistas consagrados, como Georg Lukács, André Gorz, João Bernardo, Edward P. Thompson, Robert Kurz, István Mészáros e Robert Castel, até autores contemporâneos das mais diversas áreas do conhecimento e filiações teóricas, como Claus Offe, Luciano Vasapollo, Maurizio Lazzarato, Giuseppe Cocco, Claudio Dedecca, Benjamin Coriat, Antonio Negri, Michael Hardt, Ricardo Antunes, Márcio Pochmann, Paul Singer, Antonio Thomaz Jr., Ruy Braga, Graça Druck, Maria Cristina Cacciamali, Heleieth Saffioti, Helena Hirata, José Ramalho, Marcelo Badaró, Jessé de Souza, Tom Slee, David Graeber, entre tantos outros e com aproximações e divergências entre eles, nem todos citados no presente texto.
} 
e adaptando-as, em acordo e em conflito com processos outros nos campos da técnica, da norma, das afecções e do espaço-tempo.

Assim como as próprias sociedades, o trabalho como fenômeno social é heterogêneo, desigual, complementar, solidário, produtor e produto de assimetrias - competitivo, concorrencial, predatório etc. Apesar de tomado como uma categoria monolítica e capaz de medir e ser indicativo de uma série de variáveis sociais e econômicas, o trabalho, na maior parte das vezes, não dá conta desse papel, tornando muitas análises incompletas ou mesmo equivocadas, especialmente em sociedades que, por si só, definem-se pela extrema desigualdade e pelas diferenças (qualitativas) entre os sujeitos.

É importante ressaltar ainda que o trabalho é uma das partes constitutivas do principal conflito que resulta da divisão social, o conflito de classes, ou seja, a contradição capital-trabalho. Esse conflito expressa uma contradição, pois pressupõe a exploração e a dominação de uma classe pela outra; neste sentido, não há competição ou concorrência entre as classes, visto que uma se define pela despossessão daquilo que define a outra, os meios de produção. Em outras palavras, se o capital é definido pela posse dos meios de produção - a terra, as empresas, as fábricas, a infraestrutura -, o trabalho (os trabalhadores) é definido pelo seu desapossamento, o que implica uma situação de permanente assimetria e subalternidade, ou seja, a necessidade de submeter à venda sua força de trabalho - sua energia, suas ideias e seu tempo - como forma de obtenção dos meios necessários à reprodução da própria vida.

Nesses termos e condições, a contradição está posta, pois o trabalhador nunca terá as mesmas condições objetivas de afirmação do desejo, das necessidades e opiniões que o capitalista. Por mais que o capitalista dependa da força e trabalho para a reprodução e expansão do capital, ele sempre será resguardado pelo primado da propriedade, enquanto o trabalhador sempre vai depender de uma grande articulação de classe e organização em luta para que o seu poder de enfrentamento seja eficiente ante o capital.

É claro que nesse universo de trabalhadores existe uma enorme variedade de condições para a reprodução dessa força de trabalho que se dá a partir de posições diversas dentro da estrutura social do modo de produção capitalista. Os trabalhadores constituem um conjunto quantitativamente muito amplo e qualitativamente diverso e heterogêneo no que tange ao rendimento, à formação/escolaridade, à estabilidade, ao capital social mobilizável, ao contexto social de origem imediata (família, vizinhança, comunidade). Em outras palavras, identificar o trabalho e os trabalhadores como parte de um mesmo grupo exige, muitas vezes, um esforço de reconhecimento de características que são anteriores às evidências concretas do aqui e agora.

A mesma coisa se dá quando abordamos as transformações recentes do mundo do trabalho, em especial seu processo de notória precarização ${ }^{2}$. Apesar de se tratar de um fenômeno que ganhou muita repercussão recente por conta de processos relacionados à informatização da economia, plataformização ${ }^{3}$ e desregulamentação do trabalho formal, não se pode afirmar peremptoriamente que é um processo recente.

2 cf. Antunes (2001, 2006a, 2006b, 2007, 2020b), Braga (2012, 2017), Graeber (2019), Martins (1997), Mészáros (2006), Montenegro (2014), Ramos (2012a, 2012b, 2014), Thebaud-Mony e Druck (2007) e Vasapollo (2005).

3 cf. Antunes (2020a, 2020b) e Slee (2017). 


\section{A precarização no mundo do trabalho}

Se considerarmos o conjunto de perdas em termos de estabilidade no emprego, regulamentação, direitos e poder aquisitivo dos trabalhadores, a literatura ${ }^{4}$ aponta para uma precarização que já dura mais de quatro décadas nos países centrais da Europa Ocidental e nos Estados Unidos. Essa precarização pode ser traduzida por um conjunto de medidas de flexibilização de legislações trabalhistas expressas na perda de rigor ou mesmo na suspensão de ações ao tratar de proteção social, remuneração e direitos trabalhistas.

Tal processo vem sendo acompanhado por uma forte tendência à terceirização ${ }^{5} \mathrm{e}$ à terciarização. O primeiro é referente a uma substituição da contratação direta por verdadeiras cascatas de subcontratação em termos de mão de obra empregada, o que contribui para o segundo processo, a terciarização maciça da economia, com um contingente cada vez mais amplo de trabalhadores alocados no setor terciário, em especial na prestação de serviços.

Esses trabalhadores tendem a experimentar uma fragilidade maior no que se refere à estabilidade no emprego - vide a alta rotatividade da mão de obra -, além de contratos de trabalho mais frágeis e desvantajosos em termos de direitos, assistência e salários. Neste sentido, tenham os trabalhadores maior ou menor qualificação, especialização ou mesmo escolaridade, nota-se uma inclinação descendente da curva da qualidade de vida nas mais diversas faixas de renda, repercutindo em perdas sociais $\mathrm{s}^{6} \mathrm{em}$ ampla escala.

Esses processos, não raro, foram também inaugurados e experimentados pelos países periféricos por meio da expansão do neoliberalismo, inicialmente de maneira pontual e ensaística e posteriormente de forma planejada e articulada, sobretudo por meio dos Planos de Ajuste Estrutural e suas medidas de "destravamento"/desregulamentação da economia dos países "em desenvolvimento" (cf. SOARES, 2001).

Em termos concretos, essas experiências tem sido levadas a cabo, no caso brasileiro, por uma incorporação já sacramentada da legislação das terceirizações (2017), as emendas constitucionais, que estabelecem tetos para os investimentos em educação, saúde e assistência social, tratados por governos ultraliberais como "gastos" sociais ${ }^{7}$, e as contrarreformas trabalhista (2017) e previdenciária (2019).

As consequências têm sido desastrosas e com expectativa de sensível piora no contexto da grave crise sanitária em que mergulhou o mundo com a pandemia do coronavírus ${ }^{8}$. Se nos países centrais a precarização do trabalho vem sendo responsável por uma sensível queda da qualidade de vida e um "esmagamento" da chamada classe média", com tendência ao seu desaparecimento, nos países periféricos, onde nunca vigorou de forma plena um Estado de bem-estar e uma maior equidade no acesso a bens e serviços essenciais, as consequências têm agravado o que sempre foi problemático, isto é, a atenção às necessidades mais básicas da população - moradia, alimentação, saúde -, bem como

${ }^{4}$ Thebaud-Mony e Druck (2007), Vasapollo (2005) e Braga (2017).

5 Thebaud-Mony e Druck (2007).

${ }^{6}$ cf. Kowarick (1975, 2002, 2003), Martins (1997), Valladares (1994), Souza (2012, 2018), Antunes (2020b) e Braga (2017).

7 PEC do teto de gastos, ou "PEC da morte", de 2016.

8 Em 11 de março de 2020, uma Emergência de Saúde Pública de Importância Internacional foi declarada, e a Covid-19, causada pelo vírus SARS-CoV-2, foi caracterizada pela OMS como uma pandemia, termo esse que se refere à distribuição geográfica da doença, e não, necessariamente, à sua gravidade.

9 Alguns autores vão tratar do tema do "fim da classe média" como o legado de uma era do capitalismo e sua matriz de desenvolvimento. Vide Guilluy (2020) e Souza $(2012,2018)$. 
ampliado o abismo da desigualdade de renda, tornando países como o Brasil o lugar dos extremos ${ }^{10}$ em termos de poder aquisitivo e qualidade de vida.

Outro elemento a ser considerado nesse quadro agravante é o histórico de informalidade identificado nos países periféricos, fenômeno de significativa importância rural, mas não menos relevante em áreas urbanas, metropolitanas ou não.

Os dados da PNAD/IBGE demonstram que o trabalho no Brasil é consideravelmente informal há décadas, com destaque para uma preocupante estabilidade da população ativa na informalidade. Quando restringimos o recorte analítico às áreas metropolitanas, essa proporção se reduz, porém ainda se sustentando em um patamar elevado, superior aos $40 \%$ em quase toda a série histórica. Nas áreas rurais, esses números são ainda mais impactantes. É sabido que a realidade do trabalho rural é diferente e, muitas vezes, implica relações não capitalistas de produção e reprodução da força de trabalho e, consequentemente, o não assalariamento formal. Mas tal realidade, é igualmente sabido, decorre de um processo ampliado e crescente de expulsão do pequeno agricultor em função da expansão do latifúndio e da industrialização do campo ${ }^{11}$, ao qual, muitas vezes, se agrega a ampliação da mão de obra informal, temporária/sazonal e mal remunerada.

Este é um detalhe que se deve ressaltar a respeito do trabalho formal/informal no Brasil: associar o trabalho precário ao trabalho informal como sinônimos é inadequado sob pelo menos dois aspectos ${ }^{12}$.

O primeiro aspecto é por uma questão de generalização problemática. Nem toda precarização leva à informalidade, assim como nem toda informalidade é trabalho precário. A primeira situação pode acontecer em processos de terceirização implementados em setores da indústria, comércio e prestação de serviços, em que os trabalhadores se veem em cargos e funções muito semelhantes àqueles que sempre ocuparam/desempenharam, porém com significativas perdas salariais, bem como em termos de direitos e assistência social. Já a segunda também é representativa do mercado de trabalho brasileiro, mas, de diferentes formas, teve seus exemplos multiplicados na pandemia da Covid-19.

É o caso dos trabalhadores por conta própria, que atuam em pequenas produções domésticas/familiares, e alguns profissionais liberais, que viram seu trabalho em home office se tornar "o novo normal" a partir de 2020. Professores particulares, pequenas produções de alimentos, como doces, "marmitas" e congelados, consultores, entre outros, têm em comum o fato de disporem de alguma infraestrutura domiciliar ou portátil, inclusive com certo coeficiente tecnológico. Conhecimento técnico e superior profissional qualifica seu trabalho e torna as atividades, se não bem remuneradas, ao menos aptas a uma remuneração digna e com certa estabilidade. Assim, o debate sobre a precarização induz uma discussão sobre conquistas e perdas em termos de direitos e garantias, que a questão da informalidade não esgota necessariamente.

O segundo aspecto reside no fato de que a informalidade de baixo rendimento e baixo teor tecnológico está associada a fenômenos não tão recentes e a uma série de insuficiências, carências, inacessibilidades e exclusões, que resultam em impactos geracionais em termos de qualidade de vida e reprodução da força de trabalho. O racismo estrutural e seus vetos à

\footnotetext{
${ }^{10}$ Conforme a Síntese de Indicadores Sociais (SIS) divulgada em 2019 pelo Instituto Brasileiro de Geografia e Estatística (IBGE), com dados até 2018 da Pesquisa Nacional por Amostra de Domicílio (PNAD) e da PNAD Contínua.

${ }^{11}$ Cf. Martins (2010) e Oliveira $(2001,2007)$.

${ }^{12}$ Discussão retomada a partir de Ramos (2012a, 2014).
} 
população preta e o trabalho feminino correspondem a uma ampla parcela dos chamados trabalhadores do cuidado, ou cuidadores. São babás, empregadas, zeladores, vigias/ guardadores etc., que, mesmo subalternizados em uma sociedade que reconhece muito pouco o valor e a importância do cuidado, ainda conseguem alguma inserção objetiva no mercado de trabalho, mesmo informal em sua maioria. Normalmente, essas diferentes ocupações se combinam com outras complementares e ocasionais, que garantem, assim, o mínimo necessário ao sustento das famílias, como sintetiza Montenegro (2014, p. 223-224):

diferentes estratégias de obtenção de renda se combinam para manter um padrão mínimo de consumo entre as famílias pobres nas metrópoles analisadas: multiplicidade de ocupações de um mesmo agente, realização de pequenos serviços e instalação de vendinhas na própria residência, fabricação de produtos caseiros, diversificação das tarefas no pequeno negócio familiar, dentre outras. Estes arranjos apontam para certas manifestações assumidas pela flexibilidade tropical (SANTOS, 1996a) que permitem que a renda seja não só gerada, mas também suficiente para chegar ao fim do mês.

Não se trata de equiparar informais e precários, mas reconhecer elementos estruturais constitutivos de nossa formação social-histórica, que, para além das situações e ocupações descritas anteriormente, também condena parcelas da população ativa a situações de trabalho às quais até mesmo o direito à exploração do assalariamento é negada. A uma ampla parcela dos mesmos sujeitos, homens e mulheres, em sua maioria não brancos, só resta, muitas vezes, a baixíssima remuneração, a imprevisibilidade da renda e a territorialidade instável. Tais atributos corroboram a constituição daquilo que Souza (2008) e, posteriormente, Ramos (2012a, 2012b, 2014) vão caracterizar como um hiperprecariado urbano com características geracionais de longa duração.

Existe uma organicidade nesse mesmo sistema que incorpora e tira proveito desse hiperprecariado, tornando-o parte de uma economia subterrânea, subalterna e necessária. Subterrânea pois é uma economia de "rejeitos", de práticas que se reproduzem em permanente desterritorialização, que não é reconhecida e nem visualizada pela ampla maioria, mas, de alguma forma, está presente, tem utilidade e dá sustentação a indivíduos que interligam-se a outras práticas. É subalterna porque, no que tange às relações de poder que instituem a sociedade, exerce muito pouco dos seus direitos, participa muito pouco das decisões; nesse sentido, é muito pouco autônoma, e disso resulta uma apropriação do espaço que está condicionada não só à sua própria força de organização, mas também aos interesses políticos e econômicos de outros grupos sociais. Por fim, é uma economia necessária não apenas para dar sustento, como meio de sobrevivência, àqueles que a praticam mas, como Milton Santos (1979) já havia sinalizado, a cidade só pode ser entendida a partir de uma teoria do espaço que englobe o conjunto da economia urbana, e não apenas uma parte dela (RAMOS, 2014, p. 24).

A hiperprecarização, neste sentido, pode ser entendida não apenas como um dado constitutivo do nosso mercado de trabalho e de nossa população de modo geral, mas também como um processo (em curso e sempre renovado) que se desenrola e pode se aprofundar, tomando proporções mais dramáticas e até mais brutais, na esteira de diferentes fenômenos que aparentemente só atingiriam o mercado de trabalho formal ou aquele imediatamente periférico a este, mas que sempre tem reflexos sobre a ponta mais frágil da cadeia.

Medidas como os "planos de ajuste estruturais" para a América Latina, consagradas na implantação e aprofundamento de políticas neoliberais para a região nos anos 1990 e início dos anos 2000, foram decisivas para outros fenômenos em cadeia, como a 
desindustrialização, as transformações no modo de regulação e no regime de acumulação (flexibilização e financeirização) e a redução da proteção social (SOARES, 2001). Aparentemente, tais elementos podem sugerir que a precarização e as perdas diretas incidam sobre a classe trabalhadora formal, em situações de maior ou menor exploração, mas, inevitavelmente, irá repercutir nos trabalhadores mais pobres, àqueles aos quais não apenas a formalidade não chega, mas até mesmo o direito à exploração do trabalho assalariado, a famosa "proletarização", muitas vezes é inalcançável.

O empobrecimento das cidades como reflexo imediato do acirramento do neoliberalismo vai atirar maciçamente trabalhadores pobres do setor informal em círculos ainda piores da pobreza e da informalidade. Ao empobrecimento da classe média corresponde automaticamente um empobrecimento dos já pobres, dos trabalhadores e trabalhadoras de baixa renda, principais prestadores de serviços de baixo rendimento, baixa qualificação e baixa incorporação técnica e tecnológica; daqueles que, consequentemente, preenchem setores intensivos em mão de obra. Constitui-se, assim, um heterogêneo universo de trabalhadores informais, formado por todos aqueles que sobrevivem em circunstâncias de grande vulnerabilidade ${ }^{13}$ ou mesmo perigo, morando em espaços desconfortáveis, muitas vezes insalubres ou improvisados, e exercendo ocupações estigmatizadas.

\section{Um mergulho mais profundo na precarização: a pandemia da Covid-19}

Todo esse quadro por si desfavorável no que tange às condições de vida e trabalho no país ganha contornos ainda mais dramáticos quando se instala uma crise de alcance global desencadeada pela pandemia de 2020. Essa crise, inicialmente tratada como uma crise de saúde pública, isto é, sanitária e epidemiológica ${ }^{14}$, logo vai se mostrar também uma das piores crises econômicas e sociais da história ${ }^{15}$, com proporções e impactos distantes de uma solução de curto prazo. Para as economias periféricas, em que as condições de vida já se dão em meio à instabilidade, à precariedade e à forte desigualdade de renda, as consequências têm sido nefastas.

Quando as primeiras medidas de proteção relacionadas à pandemia foram tomadas no Brasil, ainda em março de 2020, as práticas adotadas já vinham sendo implementadas há várias semanas em outras partes do mundo. China, Estados Unidos e vários países da Ásia e Europa já aplicavam medidas de restrição (com variados graus de rigidez e diferentes custos em termos de controle e autoritarismo ${ }^{16}$ ) à circulação nas áreas urbanas mais adensadas - capitais, regiões metropolitanas e algumas cidades de médio porte como tática de contenção da contaminação pelo vírus.

Os principais caminhos conhecidos até então - e meses depois continuam sendo os mais eficazes - eram a redução do contato entre as pessoas ao estritamente necessário

\footnotetext{
${ }^{13} \mathrm{cf}$. Kowarick $(2002,2003)$.

${ }^{14} \mathrm{O}$ acumulado de óbitos no mundo no primeiro trimestre de 2021 já ultrapassou muito o das guerras como a da Coreia, do Golfo (Irã/Iraque) e do Vietnã, conflitos reconhecidamente violentos e catastróficos em perdas humanas. No Brasil, já superamos em óbitos a Guerra do Paraguai (contando as baixas de ambos os lados) ou mesmo das bombas de Hiroshima e Nagasaki.

${ }^{15}$ Além da taxa de desocupação ter quase dobrado em cinco anos, de acordo com dados do Instituto Brasileiro de Geografia e Estatística (2020) a informalidade passou a englobar mais de $40 \%$ da população ocupada, resultando em um contingente de quase 40 milhões de pessoas, o maior valor em quatro anos.

${ }^{16}$ El País: O coronavírus de hoje e o mundo de amanhã, segundo o filósofo Byung-Chul Han. 22 mar 2020 (HAN, 2020).
} 
e, em caso de certa aproximação, a criação de barreiras físicas nem sempre plenamente eficazes, como o uso de máscaras e a higienização constante das mãos e do ambiente.

A primeira medida, a drástica redução do contato entre pessoas, impactou diretamente a circulação e as relações cotidianas, que são o cerne do urbano: estar junto, a proximidade entre as pessoas no viver e no morar, a circulação frenética e permanente, a pluralidade de atividades e relações, a vida predominantemente fora do ambiente doméstico a maior parte do tempo até esse momento. Tudo isso foi duramente interrompido em prol de uma prática até então pouco conhecida ou amplamente discutida: o isolamento social, que, na realidade, é um isolamento físico, visto que os contatos sociais continuam existindo, via telefone, videochamadas, ferramentas diversas de internet, que garantem a manutenção de algumas formas de trabalho, a adaptação de outras e o suprimento parcial de alguns vínculos afetivos. A redução do contato físico a certos núcleos de maior proximidade, em geral os moradores da mesma casa e, em casos mais específicos, os que partilham o mesmo ambiente de trabalho, tornou-se o grande apelo dos órgãos de gestão e controle da pandemia, assim como o desejo daqueles que dimensionavam o tamanho do risco e do problema.

Aí residia, desde sempre, contudo, o nó górdio das medidas contra a pandemia: a questão do trabalho. Para os trabalhadores impossibilitados de se isolarem em trabalho remoto ou se afastarem temporariamente das atividades, por um conjunto de fatores estruturais constitutivo das sociedades capitalistas, periféricas, fortemente desiguais e com atendimento a direitos essenciais, como alimentação, moradia e saúde, escassos para uma parcela significativa da população, o cumprimento e a manutenção do isolamento em suas exigências rigorosas instalaram um dilema e um conflito, bem como fortaleceram, servindo de ilustração e enfrentamento negativo, em muitos momentos, o discurso negacionista e anticientífico de alguns governantes e seus comandados.

Um dilema que, na verdade, é o falso dilema "saúde x economia", que rapidamente se ergueu nas comunicações dos gestores públicos, na imprensa, na mídia televisiva e até mesmo em alguns setores da ciência. Era como se o cuidado de um implicasse a exclusão ou a negligência do outro, necessariamente. Era o dilema entre manter o comércio e escolas fechados e lidar com a avalanche das demissões e a brusca freada da circulação de capital; o dilema entre manter o funcionamento das mesmas atividades (ainda que com certas restrições) e lidar com a avalanche de contaminações e suas sérias consequências doentes, hospitais superlotados, mortes e falta até de espaço em cemitérios. Demorou, no que tange à gravidade da situação, para que medidas mínimas de assistência econômica e social fossem adotadas pelos estados, como o auxílio emergencial ${ }^{17}$, abertura de linhas de crédito para empresas ${ }^{18}$, políticas de apoio e manutenção de empregos formais.

\footnotetext{
${ }^{17}$ Foi aprovado via Projeto de Lei no 9.236/17 em final de março e publicado em 2 de abril de 2020 com o valor de R \$600,00 para os já cadastrados no Programa Bolsa-Família, no CadÚnico e beneficiários de BPC e BF, com a previsão de pagamento de três parcelas prorrogáveis enquanto durasse o estado de emergência. Em meados de abril de 2020, foi aprovado novo Projeto de Lei no 873/2020 (BRASIL, 2020a), que ampliava a lista de categorias a serem beneficiadas. Muitos potenciais beneficiários, contudo, demoraram meses ou nunca sequer conseguiram acessar tal benefício por incapacidade técnica, indigência completa em termos sociais ou falta de resposta dos meios institucionais, o que dá mais relevo às nossas desigualdades estruturais.

${ }^{18}$ Em julho de 2020, o governo federal lançou o Programa Nacional de Apoio às Microempresas e Empresas de Pequeno Porte (Pronampe), linha de crédito destinada a atender pequenos negócios no Brasil que enfrentavam dificuldades por conta da pandemia da Covid-19. O acesso se deu via Banco do Brasil e Caixa Econômica Federal e recebeu incontáveis críticas de beneficiários, que argumentavam não serem admissíveis ao sistema ou aprovados na solicitação, o que inviabilizou o acesso a milhares de empresários (BRASIL, 2020b).
} 
Um conflito porque a disputa de narrativas acirrou um quadro já instalado no país pelo menos desde a segunda eleição da ex-presidente Dilma Rousseff, a polarização e o acirramento entre campos políticos mais progressistas e liberais-conservadores.

Inegavelmente, o princípio básico de tentativa de contenção da pandemia - o isolamento social e as medidas de restrição à circulação - coloca em pauta um debate profundamente geográfico, em que o ordenamento espacial e as práticas socioespaciais irão passar por processos de ressignificação, novas formas de controle e também novas formas de enfrentamento e resistências.

Tais resistências e enfrentamentos estão relacionados ao dilema que foi colocado anteriormente, isto é, à imposição de uma "escolha difícil"19 entre "salvar as pessoas ou salvar a economia”, quando a mitigação dos problemas relacionados a ela deveria ter sido encaminhada por outros meios, como acesso a crédito e auxílios financeiros facilitados. Da mesma maneira, estão também relacionados ao segundo fator o conflito aberto que se instala na sociedade brasileira há quase uma década. As disputas e até mesmo a interdição do debate entre os campos políticos no Brasil tornaram o próprio enfrentamento da pandemia - por meio das medidas amplamente aceitas como eficazes e incontornáveis diante da situação de emergência mundial - um objeto de ataque e de capitalização por sujeitos com interesses eleitorais nada virtuosos.

O negacionismo científico acerca da gravidade da doença, o boicote aos protocolos de higiene e proteção individual e a obstacularização às medidas restritivas de circulação e interação social, associados ao embate intra e entre poderes (executivo, legislativo e judiciário), bem como entre os entes da federação (União, estados e municípios), impuseram um agravamento da crise e, consequentemente, um prolongamento excessivo de um quadro grave de saúde pública e crise social.

Se o isolamento social já se mostrava, no início da crise, inviável para uma parcela considerável de trabalhadores, aqui tratados e definidos a partir de sua origem social-histórica e condições prático-objetivas de sobrevivência, com seu prolongamento indefinido ele se tornou um enclave. Temos um quadro instalado de crise aguda de acumulação e circulação capitalista, associado a quase zero investimento em medidas mitigadoras da crise, seja em assistência, seja em prevenção e saúde (como aquisição de equipamentos e insumos hospitalares ou vacinas já disponíveis no mercado desde dezembro de 2020), diante da proporção do caos.

O Brasil teve uma expressiva queda do PIB no início de 2021, com o pior resultado em trinta anos. Esse acumulado só não foi mais negativo graças ao desempenho do agronegócio, que, diferentemente dos demais setores da economia em queda, apresentou certo crescimento ${ }^{20}$, mesmo em uma situação de crise econômica e social aguda no país por ser um setor cada vez mais independente de mão de obra e também cada vez menos destinado ao consumo direto da população, ou seja, emprega pouco e é pouco impactado pelo consumo direto das famílias.

$\mathrm{Na}$ outra ponta da cadeia, entre os trabalhadores pobres, (hiper)precarizados e que têm sua situação gravemente afetada na pandemia, é possível enxergar uma certa diversidade

\footnotetext{
${ }^{19}$ Parafraseando o Editorial do Estadão, de 8 de outubro de 2018 (ESTADÃO, 2018).

${ }^{20}$ Segundo o IBGE, "em 2020, os serviços encolheram 4,5\% e a indústria, 3,5\%. Somados, esses dois setores representam $95 \%$ da economia nacional. Por outro lado, a agropecuária cresceu 2,0\%. [...] O consumo das famílias teve o menor resultado da série histórica (-5,5\%). Isso pode ser explicado, segundo a coordenadora de Contas Nacionais, principalmente pela piora no mercado de trabalho e a necessidade de distanciamento social" (AGÊNCIA DE NOTÍCIAS, 2021).
} 
de situações, e em todas elas a vulnerabilidade social ${ }^{21}$, a exposição ao risco de doença, a instabilidade de renda, o endividamento ${ }^{22}$ das classes subalternas e precarizadas e a baixa qualidade de vida são fatores cumulativos. Vemos um conjunto diverso de prestadores de serviços diretos de baixa remuneração (manutenção, entregas, cuidado doméstico e patrimonial), balconistas de setores essenciais (mercados e farmácias) e outros trabalhadores ainda mais precarizados que vivem de atividades informais subalternas, sejam elas ocasionais ou permanentes, como camelôs, ambulantes, "guardadores de carro", entre outras pequenas formas de comércio e prestação de serviços urbanos, com a sentença diária de não ter escolha nenhuma em termos de sustento.

Esses trabalhadores estão permanentemente sob ameaça e compõem a parcela mais exposta ao contágio, além, é claro, de quem trabalha diretamente com doentes em hospitais e unidades básicas de saúde. Para esses trabalhadores pobres, seja do primeiro grupo (os trabalhadores de atividades essenciais), seja do segundo (trabalhadores hiperprecarizados), o isolamento não é uma opção. No primeiro caso, isso se deve por serem atividades indispensáveis em uma sociedade em que a tecnologia ainda não dispensou certos postos de trabalho e suas funções. No segundo caso, isso ocorre porque a opção do isolamento não é de fato uma opção se ela implica não trazer o alimento diário para casa. Nessas situações, ficar em casa significa passar fome de fato.

Há um elo intermediário nessa cadeia que é uma parte considerável dos trabalhadores, os quais constituem hoje os chamados plataformizados (ANTUNES, 2020a) ou uberizados (SLEE, 2017). Esses trabalhadores formam um complexo resultado de perdas sucessivas do mercado de trabalho formal, o qual "empurrou" milhares de desempregados ${ }^{23}$ para o "microempreendedorismo individual", muitos deles investindo suas indenizações rescisórias e fundos de garantia na compra do "novo instrumento de trabalho" - bicicletas, equipamentos de proteção individual, motocicletas ou automóveis - para aderir ao modelo inaugurado no ramo de transportes de passageiros e entregas. Porém, também são resultado - e nesse caso o Brasil é um laboratório para importantes constatações de uma situação de permanente exclusão de parcelas de trabalhadores, em geral jovens, negros e moradores de periferias, do mercado de trabalho formal.

Esses jovens, desde cedo, deixam de enxergar a educação e a formação profissional como uma possibilidade de ascensão, por uma dificuldade histórica de inserção de tais grupos em setores formais e qualificados da economia, além da imposição de uma subjetividade neoliberal a que todos estamos expostos e que vai conformar cidadãos que pensam e agem de maneira correspondente ao perfil do sujeito neoliberal, compatível com o governo empresarial, ambos descritos por Dardot e Laval (2016). A ideia da "empresa de si como ethos da autovalorização" (idem, p. 333), da "autonomia" como ambição do trabalho "livre",

[...] transformações no mundo do trabalho materializadas na precarização desse segmento social que alimentam a informalização das economias e, com ela, a adoção do termo "autônomo" como um eufemismo para a nova situação a que está exposto não só o trabalhador urbano, mas também o trabalhador agrícola. Essa "eufemização" faz parte de uma estratégia de atuação do capitalismo "pós-industrial" que envolve novos tipos de propaganda (new marketing) e uma nova psicologia social: o trabalhador

\footnotetext{
${ }^{21}$ cf. Kowarick $(2002,2003)$.

${ }^{22}$ Cavallero e Gago (2020).

${ }^{23}$ Ver Pochmann (2006).
} 
que não tem carteira assinada, direitos trabalhistas e acesso a benefícios sociais, não é informal, é "autônomo"; aquele que possui esses direitos por estar submetido a uma relação de assalariamento, por sua vez, não é mais um empregado (termo carregado de subjetividade), é agora um "colaborador" da empresa; os trabalhadores terceirizados e temporários não são mais subcontratados, mas “cooperativados" ou ainda "parceiros", e assim sucessivamente. Essa ressignificação da economia, no sentido de incutir novo significado aos cargos, funções e papéis sociais, em meio às novas questões do mercado e da sociedade, hipertrofiaram o segmento dos "trabalhadores autônomos". Cada vez mais, se inserem na informalidade quantidades maiores de trabalhadores desempregados, precarizados, (super)explorados, contribuindo para uma banalização da ideia de autonomia (RAMOS; RODRIGUES, 2010, p. 6-7).

Esse mito da flexibilidade da escolha da jornada e da forma do trabalho torna-se um mantra que reproduz a lógica do (auto)convencimento, até mesmo para aqueles que já teriam cumprido com sua parcela de contribuição como força de trabalho ativa. Os trabalhadores idosos, os aposentados formais e aqueles que nunca conseguiram esse direito se tornam alvos de uma incorporação perversa associada a um desprezo sistêmico.

Em se tratando dos trabalhadores que já atingiram a idade para a aposentadoria, mas permanecem ativos no mercado de trabalho formal, informal, plataformizado, uberizado etc., há seguramente um prolongamento da vida ativa por hipossuficiência econômica, e, concomitantemente, torna-se comum o papel de idosos chefiando famílias, de homens e mulheres com renda oriunda de aposentadorias, pensões e auxílios ou que permanecem no mercado de trabalho contribuindo para o sustento dos mais jovens.

Diante da hegemonia da subjetividade neoliberal, a permanência do trabalhador idoso no mercado de trabalho é vista como uma contingência. Ao mesmo tempo, suas limitações e maior vulnerabilidade - à violência, aos acidentes urbanos e, na atualidade da pandemia da Covid-19, ao risco de contaminação com riscos agravantes - não são tratadas como um problema real, como dados a serem considerados para o mercado de trabalho. Contraditória e concomitantemente, esses trabalhadores não são imunes a uma subjetividade etarista que os vê como aqueles que já não interessam à economia, nem como produtivos, nem como consumidores, ou seja, tratar-se-iam de populações descartáveis. Nesse sentido, a assimilação e a reprodução da ideia de que "os idosos são os que mais morrem por complicações da Covid” - consequentemente, a doença não seria um risco social -, de fato reforçam uma interpretação darwinista do risco para a qual os idosos estão a cumprir seu único propósito, que é morrer.

Todos os trabalhadores e trabalhadoras, jovens ou adultos desempregados, aposentados ou não, estão entregues a (já não tão) novas formas de exploração e espoliação pelo trabalho.

A exploração é facilmente identificada e reside na baixíssima remuneração por hora de trabalho em comparação com o lucro dos capitalistas e investidores. Os sites de agenciamento dos trabalhadores indicam rendimentos que variam entre $\mathrm{R} \$ 9$ a $20^{24}$ por hora trabalhada para atividades que vão da entrega de comida e mercado a pé e de bicicleta, por exemplo, até o transporte particular de passageiros com automóvel. Trata-se de uma média bastante baixa, independentemente das atividades, em si mesmas distintas e com diferentes graus de responsabilidades por parte dos envolvidos. É baixa especialmente se comparada ao valor de mercado dessas empresas, tendo em vista o dinheiro por elas movimentado anualmente e sua participação em mercados financeiros globais. A título

${ }^{24}$ Salário (2020). 
de ilustração, a Movile, proprietária da marca $i F o o d$, estimava o valor de mercado da empresa em 2018 em mais de 1 bilhão de dólares ${ }^{25}$, não tendo praticamente nenhum encargo fiscal, trabalhista ou previdenciário.

Já a espoliação reside nos detalhes. Desde a flexibilização de legislações ou mesmo a inexistência delas, como no caso das variadas formas do trabalho por aplicativos, até as mudanças mais recentes que têm resultado em perdas de garantias e direitos ${ }^{26}$ aos trabalhadores são exemplos clássicos, mas longe de serem os únicos. O endividamento em âmbito individual, doméstico e social de maneira ampla - tem sido uma das formas mais eficientes, na atualidade, de drenar recursos dos trabalhadores mais pobres, aquilo que Luci Cavallero e Verónica Gago vêm caracterizando como "exploração financeira da população 'assistida", isto é "um diferencial nas taxas de juros que se aplicam a esses setores, logo que são caracterizados como 'de risco'” (CAVALLERO; GAGO, 2020, p. 39).

Sujeitos a salários ou rendas (no caso dos trabalhadores por conta própria, não assalariados) insuficientes ao sustento das famílias, ou incapazes de garantir acesso a determinados serviços e bens de consumo, muitos trabalhadores e trabalhadoras recorrem à dívida como forma de driblar a falta de recursos imediatos.

É um ponto notável o encadeamento e a superposição das diversas modalidades de endividamento. Por um lado, trata-se de priorizar o pagamento das dívidas "formais", já que o seu descumprimento acarreta em ficar registrado em plataformas de "inabilitação" financeira (como o Veraz na Argentina ou a Serasa no Brasil), que se converte em um impedimento a novos créditos. Para tentar estar em dia com esse tipo de dívidas, muitas vezes se recorre a outro patamar de endividamento: o informal, que compreende uma variada rede de formas usurárias. Esta se caracteriza por duas coisas: taxas de juro ainda mais altas e formas de violência ainda mais fortes frente à inadimplência no pagamento. Assim, uma dívida se paga com mais dívida. Desse modo, conformamse verdadeiras "redes" de dívida, que vão se refinanciando entre si, habilitando níveis diversos de juros, formas de ameaça por descumprimento e distintos cronogramas de vencimento (CAVALLERO; GAGO, 2020, p. 41).

Tal endividamento vem sustentando uma cadeia de consumo e assistência ampla, indo além do crediário de bens duráveis, imóveis e do crédito rotativo e alcançando serviços de primeira necessidade, como tratamentos de saúde, aluguel de imóveis, custeio de educação/qualificação, na forma de pagamento de mensalidades ${ }^{27}$ em cursos técnicos e no ensino superior ${ }^{28}$, ou mesmo o pagamento de outras dívidas.

Some-se a esse quadro os juros historicamente elevados no país ${ }^{29}$, e a drenagem configurada no comprometimento total da renda do trabalhador com custeio de dívidas,

\footnotetext{
${ }^{25}$ Pacheco (2018).

${ }^{26}$ A Reforma Trabalhista (2017) e a Reforma da Previdência (2019) são dois exemplos recentes já citados.

${ }^{27}$ A formação profissional via ensino superior e técnico tem se apresentado como aposta na melhora da qualidade de vida por parte de alguns trabalhadores e, concomitantemente, como um grande filão do mercado da educação privada, a qual tem diversificado seu campo de atuação via mercado financeiro, em um primeiro momento com as estratégias de abertura de capital e inserção no mercado de ações, e depois também via atuação como operador de financiamentos e sistemas de crédito próprios, configurando um bypass das linhas de acessos a crédito via Estado ou instituições financeiras tradicionais. Isso tem contribuído para um quadro de endividamento corrente da população trabalhadora, fruto do crédito pessoal tradicional - cartões, cheque especial, crédito consignado, variados cardápios de empréstimos e financiamentos -, na aquisição de bens duráveis e mercadorias banais, mas também nas novas e variadas opções de acesso aos serviços como saúde e educação, via financeirização das opções no mercado.

${ }^{28} \mathrm{O}$ ensino superior está cada vez mais financeirizado via sistema de crédito educacional (FIES) e por subsídio direto às empresas educacionais (PROUNI), bem como por meio de grupos que têm capital aberto e fundos de investimento no setor da educação (INSTITUTO HUMANITAS UNISINOS, 2021).

${ }^{29}$ Paulo Gala (2019).
} 
da dilapidação de seu escasso patrimônio e, por vezes, da regressão de sua qualidade de vida por incapacidade de arcar com os compromissos financeiros assumidos perfaz um retrato da espoliação da classe trabalhadora na atualidade, catalisador da crescente acumulação na outra ponta da cadeia.

O endividamento das camadas mais pobres da sociedade e o processo mais amplo de financeirização do mercado capitalista se impõem como mais uma faceta do neoliberalismo em curso há algumas décadas. É a subjetivação funcionando como disseminadora da crença de que todos podem ser empreendedores e de que o sucesso econômico individual é uma questão de esforço, resiliência e capacidade de inovação.

Tais argumentos e crenças parecem ter se aprofundado nas situações de crise, em especial na mais recente, causada pela pandemia da Covid-19, pois fazem transcender as imposições objetivas da vida material, as fraquezas e adversidades reais, substituindo-as por uma crença messiânica no sucesso individual. A principal consequência da emergência desse "sujeito neoliberal", conforme Dardot e Laval, é a erosão da noção de cidadania, ou o que Milton Santos vai denominar "cidadania atrofiada".

Em nenhum outro país foram assim contemporâneos e concomitantes processos como a desruralização, as migrações brutais desenraizadoras, a urbanização galopante e concentradora, a expansão do consumo de massa, o crescimento econômico delirante, a concentração da mídia escrita, falada e televisionada, a degradação das escolas, a instalação de um regime repressivo com a supressão dos direitos elementares dos indivíduos, a substituição rápida e brutal, o triunfo, ainda que superficial, de uma filosofia de vida que privilegia os meios materiais e se despreocupa com os aspectos finalistas da existência e entroniza o egoísmo como lei superior, porque é o instrumento da busca da ascensão social. Em lugar do cidadão formou-se um consumidor, que aceita ser chamado de usuário (SANTOS, 2007, p. 25).

É importante destacar que a primeira edição desse texto é de 1987 e já sinaliza, há mais de trinta anos, características e fragilidades tão caras atualmente e agravadas com a crise instalada pela pandemia de 2020 .

\section{A espacialidade da hiperprecarização na pandemia da Covid-19}

Os pobres das cidades são aqueles que não só têm acesso restringido ao consumo de bens e serviços cada vez mais diversificados e sedutores em um mercado que toma todos os espaços e mentes, por não terem renda compatível com tal comportamento, mas também têm limitadas, dentro desse mesmo mercado e dessa mesma sociabilidade, as suas condições mais básicas de existência. Moradia e trabalho nesse contexto socioespacial se definem pela extrema precariedade, condição incompatível com o discurso dominante do "sucesso individual alcançável por todos"; portanto, altamente frustrante.

Para muitos, essa realidade pode ser ainda mais brutal, se considerarmos a interseccionalidade constitutiva do trabalho precário a partir de fatores já mencionados neste texto. Raça, classe e gênero não são dissociáveis quando se pretende falar de trabalho de baixa renda, assim como é inevitável falar de sua espacialidade periférica e seu grau de exposição a riscos ${ }^{30}$ variados, ou seja, em acordo com Souza (2005, p. 192), “a metrópole

${ }^{30} \mathrm{cf}$. Kowarick (2002). 
é, também, cada vez mais, um locus da pobreza e da miséria, assim como, por tabela, da insegurança e da violência”.

A periferia é constituída não só da zona periurbana, a franja da cidade, mas de favelas, ocupações, loteamentos irregulares, incluídos ou não nas áreas centrais. Trata-se, portanto, da

[...] pobreza que se materializa nos espaços segregados, nas periferias precariamente incluídas, nos espaços preenchidos por atividades econômicas subalternas, nas redes de informalidade e precariedade (como o comércio ambulante, os camelôs, os pequenos prestadores de serviços, os vendedores de drogas a varejo, a prostituição, o jogo ilegal etc.), nas paisagens conflitantes produzidas por miséria e riqueza lado a lado, por mundos tão próximos e em alguns sentidos, tão distantes (RAMOS, 2012a, p. 101).

Esses espaços são resultado de uma característica marcante da habitação no Brasil: o déficit habitacional, o qual consiste na quantidade de novas unidades habitacionais necessárias para atender à demanda da população, isto é, àqueles que não têm casa e não podem pagar por uma. É importante ressaltar que nem todos os imóveis regularizados, destinados ou não à moradia, cumprem a sua função, ou seja, servem efetivamente de moradia para alguém. Mas muitos desses imóveis estão vazios há décadas por questões judiciais, processos por dívidas, espólio, penhora etc., ou cumprem, fechados, desocupados e em processo de deterioração, exclusivamente a função de reserva de valor do solo urbano, contribuindo para a especulação imobiliária nas cidades.

Quando falamos em déficit habitacional, significa, em termos práticos, que a falta do acesso à moradia digna vai impelir as pessoas a dar soluções emergenciais ao seu problema concreto que é a falta de um teto. $O$ resultado são os processos de ocupação de terrenos, em sua maioria públicos, para autoconstrução de habitações e a ocupação de imóveis já edificados (em bem menor proporção e, em geral, tão ou mais precários quanto as moradias que são fruto da autoconstrução em favelas, dado o grau de deterioração desses espaços). Neste sentido, se o déficit habitacional sozinho não diz tudo sobre as injustiças sociais, ele, acompanhado do cálculo dos domicílios vagos e recuperados pela União, aponta para o quão desigual é a apropriação do espaço nas cidades do Brasil e em muitos outros lugares do mundo.

No Brasil, o déficit habitacional era de quase 7 milhões de domicílios (cerca de 9\% da população ${ }^{31}$ ) em 2015, dos quais aproximadamente 5 milhões estão em favelas e periferias precárias. Segundo dados do último Censo do IBGE, na cidade de São Paulo, 11\% da população habita esses espaços, enquanto na cidade do Rio de Janeiro esse valor chega a $22 \%$. Não é a maior em termos proporcionais, mas faz do Rio de Janeiro o líder nacional em número absoluto de moradores de favelas. Outras capitais do país também chamam atenção pela proporção, como Salvador, com 33\%, e Belém, com $54 \%$ da população, além de Fortaleza, Recife, Belo Horizonte, Manaus e São Luís, com proporções de 13 a 23\% de moradias em favelas em relação ao total de moradias, segundo dados (já desatualizados) do Censo 2010 do IBGE. No mundo, esse valor vai ao cômputo de 1,6 bilhão de domicílios $^{32}$, o que significa que aproximadamente $25 \%$ da população mundial vive sem infraestruturas, saneamento básico, acesso a serviços públicos essenciais e com escassez de água e de eletricidade.

\footnotetext{
${ }^{31}$ Segundo dados da Fundação João Pinheiro (2015).

${ }^{32}$ Dados da ONU Habitat.
} 
São trabalhadoras e trabalhadores pobres, em sua maioria fora do mercado de trabalho formal, desempenhando atividades precárias, instáveis e mal remuneradas, com inadequação das moradias que afeta decisivamente sua qualidade de vida. Essa inadequação, segundo critérios definidos para finalidade de cálculo do déficit habitacional, está relacionada à precariedade estrutural, à coabitação familiar, ao ônus excessivo com aluguel que compromete a renda familiar e ao adensamento excessivo das unidades habitacionais.

Não se trata de elementos novos ou de uma conjuntura recente. Tais dados não se baseiam em mudanças de metodologia nos levantamentos e estudos. São parte estruturante de nossa sociedade e dizem muito sobre a história da qualidade de vida e do desenvolvimento socioespacial nas cidades brasileiras. Neste sentido, os fatores de natureza socioespacial ou ambiental são elementos centrais para entendermos o agravamento da pandemia e quais são os grupos sociais e os indivíduos mais afetados por esse evento crítico em saúde pública.

É nas periferias, favelas e ocupações urbanas que moram os trabalhadores e trabalhadoras mais expostos ao risco do contágio, em razão de seus tipos de atividade, fortemente dependentes do contato interpessoal; por causa de seu grau de exposição diária, em geral sujeitos ao baixo isolamento em ruas, avenidas, espaços de grande circulação de pessoas e longo tempo de deslocamento em transportes públicos superlotados; por sua baixa capacidade de autoproteção e autocuidado, tendo em vista o custo e o acesso aos requisitos mais simples destas práticas, a higiene pessoal (acesso à água tratada, saneamento básico e sabão) e máscaras de proteção individual. Além disso, tais espaços são predominantemente habitados por pretos $^{33} \mathrm{e}$ indígenas, que correspondem a quase metade dos trabalhadoras e trabalhadores pobres, informais precários, habitantes dos espaços periféricos em comparação aos brancos ${ }^{34}$.

Pretos e indígenas também compõem quase $2 / 3$ dos desempregados e dos subutilizados no mercado de trabalho brasileiro, e a maioria são mulheres chefiando famílias com rendimentos insuficientes ${ }^{35}$. São essas mesmas mulheres as "cuidadoras" em sentido geral, dentro e fora das instituições. São enfermeiras e técnicas em saúde, profissionais de zelo, manutenção e limpeza, empregadas domésticas, operadoras de caixas em supermercados, balconistas em comércios de pequeno porte, professoras nas etapas iniciais da educação. Em geral, elas têm em comum o fato de acumularem a função de mães e chefes de família, o que corrobora a ampliação da carga de trabalho e/ou a redução de rendimentos da família, e, na atualidade pandêmica, estão mais expostas ao risco de contaminação e disseminação entre os familiares.

Delimitando e qualificando os pobres das cidades brasileiras e entendendo sua espacialidade em termos de moradia, atividades, ocupações e circulação urbana, entendemos também que o trabalho não é apenas mais um atributo da vida, desconectado de uma historicidade e uma de espacialidade (material e social). O espaço, em sua totalidade complexa e contraditória, que se (re)produz em formas, funções, processos e estruturas, categorias propostas por Santos (2008) para análise do espaço geográfico, enseja a espacialidade humana como reflexo e como meio e condição social, e não como acessório ou secundário nas relações sociais. Em outras palavras, as relações sociais são relações espaciais.

\footnotetext{
${ }^{33}$ Dos moradores de favelas, $72 \%$ se declaram "negros", segundo a IpeaDATA (1991-2000).

${ }^{34}$ Que são cerca de 35\% nesses mesmos espaços, segundo o Censo do Instituto Brasileiro de Geografia e Estatística (2010).

${ }^{35}$ Segundo o Instituto Brasileiro de Geografia e Estatística (2010), 63\% das famílias comandadas por mulheres negras estão abaixo da linha de pobreza.
} 
A estrutura diz respeito à própria sociedade, sua economia, política e cultura; o processo remete às articulações, ao conjunto de ações que movimenta a estrutura e a transforma permanentemente; a função se refere à redefinição constante das formas em acordo com os processos que comandam a reprodução social - formas essas que são produtos/ criações humanas e se manifestam em diferentes escalaridades.

Uma sociedade capitalista, periférica e subordinada a relações assimétricas de poder em diferentes níveis escalares e institucionais se expressa em uma estrutura profundamente desigual e injusta em termos de direitos e acessos. Consequentemente, as articulações oriundas dessa estrutura serão conservadoras e tendem a reproduzir as injustiças, ou seja, os privilégios e as exclusões em diferentes setores da sociedade, no mercado de trabalho, no direito à moradia, no acesso à justiça etc. Portanto, a cidade como forma, a segregação urbana, a apropriação desigual do espaço e a circulação condicionada a fatores de ordem estrutural ajudam a compreender a (hiper)precariedade do trabalho, a (des)funcionalidade de algumas formas.

$\mathrm{O}$ aprofundamento da crise social sistêmica que vivemos no último ano diz muito para a compreensão desse edifício teórico. $\mathrm{O}$ aumento da pobreza extrema é um dado concreto produzido com/pela pandemia. Segundo a PNAD Covid-19/IBGE, a "população abaixo da linha de pobreza extrema aumentou em todas as regiões brasileiras", assim como a desigualdade, que teve aumento, principalmente, com a redução e a posterior retirada do auxílio emergencial pelo governo federal.

O aumento da população em situação de rua é um dado que sustenta tal afirmação e uma realidade que chama a atenção no país, sobretudo nas capitais e regiões metropolitanas. Tal ampliação já havia sido registrada desde o último estudo publicado pelo IPEA em $2016^{36}$. A atualização desses dados para o período da pandemia ainda é incerta, mas as relações que se estabelecem não apontam para um prognóstico positivo. A publicação de uma pesquisa de percepção recente indica que, para $43 \%$ dos brasileiros, "o número de moradores de rua em suas cidades aumentou no último ano"37.

Como pensar e planejar o isolamento com (auto)proteção para quem não tem casa ou vive a maior parte do tempo na rua? A tendência ao aprofundamento desse quadro desde sempre existente e por si dramático pode conduzir uma parte não desprezível, mas historicamente desprezada e relegada à indigência, à eliminação física.

Trata-se de uma população cujo grau de abandono e exclusão impedem até mesmo o acesso à assistência social e auxílios de emergência; uma população não contada e não identificável cujo autoisolamento imposto pela conjuntura é impossível diante de um heteroisolamento estrutural e, consequentemente, permanente.

\section{Considerações finais}

No Brasil, já ultrapassamos a marca dos 260 mil $^{38}$ mortos pela Covid-19 e pelo descaso do poder público. E a taxa de desocupação se aproxima dos 15\%, o que significa a ausência de trabalho e renda, e não apenas o desemprego formal.

\footnotetext{
${ }^{36}$ O IPEA ressalta que não existem dados consolidados oficiais sobre a população em situação de rua no Brasil, algo que é contornado com a utilização de dados disponibilizados pelos municípios via cadastro único de assistência social, o que, no entanto, gera muitas inconsistências.

${ }^{37}$ Pesquisa realizada pelo Datafolha em dezembro de 2020 (SANT’ANNA, 2020).

${ }^{38}$ Número referente à primeira semana de março de 2021, disponibilizado em https://covid.saude.gov.br/, dados das Secretarias Estaduais de Saúde.
} 
Como já vínhamos apontando desde abril de 2020, repensar o trabalho, o emprego, as necessidades e o consumo será um dos grandes legados da pandemia da Covid-19, o que significa caminhos abertos à reflexão, ainda que balizados por um certo pessimismo quanto aos reais resultados de tal esforço.

Continuamos acreditando que entender os limites de uma economia baseada na exploração e espoliação dos trabalhadores e trabalhadoras, na extração extrema de mais-valia, no endividamento das famílias e no individualismo como antídoto para a crise sistêmica é uma condição relativamente familiar à sociedade brasileira que vem sendo potencializada pelo caos.

O mesmo caos vai expor de forma crescente a pobreza extrema, visível e invisível, materializada, entre outras formas, na população em situação de rua e no trabalho hiperprecarizado; vai expor cada vez mais nossas assimetrias históricas e nossas entranhas. "Não será 'só' o desemprego, a incapacidade de gerar a própria subsistência, o grande choque da pandemia. Será, também, a demarcação clara entre quem vive e quem morre, quem tem como e onde se 'proteger' e quem simplesmente não tem" (RAMOS, 2020). Que a esperança de algum potencial transformador seja nossa utopia.

\section{Referências Bibliográficas}

AGÊNCIA DE NOTÍCIAS. PIB cresce 3,2\% no $4^{\circ}$ tri, mas fecha 2020 com queda de 4,1\%, a maior em 25 anos. 3 mar. 2021. Disponível em: <https://agenciadenoticias.ibge.gov.br/agencia-noticias/2012-agenciade-noticias/noticias/30166-pib-cresce-3-2-no-4-tri-mas-fecha-2020-com-queda-de-4-1-a-maior-em25-anos>. Acesso em: 15 mar. 2021.

ANTUNES, R. Os sentidos do trabalho: ensaio sobre a afirmação e a negação do trabalho. São Paulo: Boitempo, 2001.

ANTUNES, R. A era da informatização e a época da informalização: riqueza e miséria do trabalho no Brasil. In: ANTUNES, R. (Org.). Riqueza e miséria do trabalho no Brasil. São Paulo: Boitempo, 2006a.

ANTUNES, R. Construção e desconstrução da legislação social no Brasil. In: ANTUNES, R. (Org.). Riqueza e miséria do trabalho no Brasil. São Paulo: Boitempo, 2006b.

ANTUNES, R. Dimensões da precarização estrutural do trabalho. In: DRUCK, G.; FRANCO, T. (Org.). A perda da Razão social do trabalho: terceirização e precarização. São Paulo: Boitempo, 2007.

ANTUNES, R. Trabalho intermitente e uberização do trabalho no limiar da indústria 4.0. In: ANTUNES, R. (Org.). Uberização, trabalho digital e indústria 4.0. São Paulo: Boitempo, 2020a.

ANTUNES, R. O privilégio da servidão: o novo proletariado de serviços na era digital. São Paulo: Boitempo, 2020b.

BRAGA, R. A política do precariado: do populismo à hegemonia lulista. São Paulo: Boitempo, 2012.

BRAGA, R. A rebeldia do precariado: trabalho e neoliberalismo no sul global. São Paulo: Boitempo, 2017.

BRASIL. Decreto no 10.316, de 7 de abril de 2020. Regulamenta a Lei no 13.982, de 2 de abril de 2020, que estabelece medidas excepcionais de proteção social a serem adotadas durante o período de enfrentamento da emergência de saúde pública de importância internacional decorrente do coronavírus (covid-19). Diário Oficial da República Federativa do Brasil, Brasília, DF, 7 abr. 2020a. Disponível em: <http:// www.planalto.gov.br/ccivil_03/_ato2019-2022/2020/decreto/D10316.htm>. Acesso em: 15 mar. 2021.

BRASIL. Micro e pequenos empresários contam com linha de crédito durante pandemia. Brasília, $2020 \mathrm{~b}$. Disponível em: <https://www.gov.br/pt-br/noticias/trabalho-e-previdencia/2020/07/micro-e-pequenosempresarios-contam-com-linha-de-credito-durante-pandemia>. Acesso em: 15 mar. 2021.

CAVALLERO, L.; GAGO, V. Extrativismo financeiro: a dívida como uma ofensiva do capital contra os setores subalternos. In: RODRIGUEZ, G. (Org.). O sistema financeiro e o endividamento das mulheres. Rio de Janeiro: Instituto Equit Gênero, Economia e Cidadania Global, 2020.

DARDOT, P.; LAVAL, C. A nova razão do mundo: ensaio sobre a sociedade neoliberal. São Paulo: Boitempo, 2016. 
ESTADÃO. Uma escolha muito difícil. São Paulo, 8 out. 2018. Disponível em: <https://opiniao.estadao. com.br/noticias/geral,uma-escolha-muito-dificil,70002538118>. Acesso em: 15 mar. 2021.

FUNDAÇÃO JOÃO PINHEIRO - FJP. Centro de Estatística e Informações. Déficit habitacional no Brasil 2011-2012. Belo Horizonte: FJP, 2015.

GALA, P. Breve histórico da taxa de juros real no Brasil. 2019. Disponível em: <https://www.paulogala. com.br/breve-historico-da-taxa-de-juros-real-no-brasil-2/>. Acesso em: 5 mar. 2021.

GRAEBER, D. Bullshit jobs, a theory. EUA: Simon \& Schuster, 2019.

GUILLUY, C. O fim da classe média:a fragmentação das elites e o esgotamento de um modelo que já não constrói sociedades. Record, 2020.

HAN, B.-C. O coronavírus de hoje e o mundo de amanhã, segundo o filósofo Byung-Chul Han. El País, 22 mar. 2020. Disponível em: <https://brasil.elpais.com/ideas/2020-03-22/o-coronavirus-de-hoje-e-omundo-de-amanha-segundo-o-filosofo-byung-chul-han.html>. Acesso em: 15 mar. 2021.

INSTITUTO BRASILEIRO DE GEOGRAFIA E ESTATÍSTICA - IBGE. Sinopse do censo demográfico: 2010. Rio de Janeiro: IBGE, 2011.

INSTITUTO BRASILEIRO DE GEOGRAFIA E ESTATÍSTICA - IBGE. Pesquisa Nacional por Amostra de Domicílios (PNAD) contínua. Rio de Janeiro: IBGE, 2020. Disponível em: <https://www.ibge.gov. br/indicadores\#desemprego>. Acesso em: jun. 2021.

INSTITUTO HUMANITAS UNISINOS - IHU. Kroton Educacional: 'Em termos de educação pública nunca experimentamos um inimigo com uma força social tão concentrada como esse’. 2021. Disponível em: <http://www.ihu.unisinos.br/78-noticias/578444-kroton-educacional-em-termos-de-educacaopublica-nunca-experimentamos-um-inimigo-com-uma-forca-social-tao-concentrada-como-esse $>$. Acesso em: 5 mar. 2021.

KOWARICK, L. Capitalismo e marginalidade na América latina. Rio de Janeiro: Paz e Terra, 1975.

KOWARICK, L. Viver em risco: sobre a vulnerabilidade no Brasil urbano. Novos Estudos, São Paulo, v. 63, p. 9-29, 2002.

KOWARICK, L. Sobre a vulnerabilidade socioeconômica e civil: Estados Unidos, França e Brasil. Revista Brasileira de Ciências Sociais, São Paulo, v. 18, n. 51, 2003.

MARTINS, J. S. Exclusão social e a nova desigualdade. São Paulo: Paulus, 1997.

MARTINS, J. S. O cativeiro da terra. São Paulo: Contexto, 2010.

MÉSZÁROS, I. Desemprego e precarização: um grande desafio para a esquerda. In: ANTUNES, R. (Org.). Riqueza e miséria do trabalho no Brasil. São Paulo: Boitempo, 2006.

MONTENEGRO, M. R. Globalização, trabalho e pobreza nas metrópoles brasileiras. São Paulo: Annablume, 2014.

OLIVEIRA, A. U. A longa marcha do campesinato brasileiro: movimentos sociais, conflitos e Reforma Agrária. Estudos Avançados, São Paulo, v. 15, n. 43, p. 185-206, 2001. http://dx.doi.org/10.1590/S010340142001000300015.

OLIVEIRA, A. U. Modo de produção capitalista, agricultura e reforma agrária. São Paulo: FFLCH, 2007.

PACHECO, P. iFood terá R\$ 1,9 bi em investimentos. Estado de Minas, 14 nov. 2018. Disponível em: $<$ https://www.em.com.br/app/noticia/economia/2018/11/14/internas_economia,1005531/ifood-terar-1-9-bi-em-investimentos.shtml>. Acesso em: 4 mar. 2021.

POCHMANN, M. Desempregados do Brasil. In: ANTUNES, R. (Org.). Riqueza e miséria do trabalho no Brasil. São Paulo: Boitempo, 2006.

RAMOS, T. T. As barricadas do hiperprecariado urbano: das transformações no mundo do trabalho à dinâmica sócio-espacial do movimento dos sem-teto no Rio de Janeiro. Tese-Programa de Pós-graduação em Geografia, Universidade Federal do Rio de Janeiro, 2012a.

RAMOS, T. T. Informalidade e hiperprecarização, economia popular urbana e economia solidária. Revista Território Autônomo, [S.l.], v. 1, 2012 b.

RAMOS, T. T. Uma geografia da pobreza urbana: informalidade e precarização do trabalho. Boletim Campineiro de Geografia, Campinas, v. 4, n. 1, 2014.

RAMOS, T. T. Pandemia é pandemia em qualquer lugar: vivendo a crise da Covid-19 de fora dos grandes centros. Espaço e Economia, v. 18, 2020. Disponível em: <http://journals.openedition.org/ espacoeconomia/11406. Acesso em: 9 mar. 2021.

RAMOS, T. T.; RODRIGUES, G. B. Trabalhador autônomo ou 'trabalhador autônomo'? Do o trabalho como prática heterônoma nos espaços de outrem, ao trabalho como prática de resistência e criação de 
espaços insurgentes. In: ENCONTRO NACIONAL DE GEÓGRAFOS, 16., 2010, Porto Alegre. Anais... Porto Alegre: AGB Porto Alegre, 2010.

SALÁRIO. Quanto ganha um entregador do Rappi, iFood, Uber Eats e Loggi. 2021. Disponível em: <https:// www.salario.com.br/quanto-ganha/entregador-rappi-ifood-uber-eats-loggi/>. Acesso em: 4 mar. 2021.

SANT'ANNA, E. Para 43\% dos brasileiros, número de moradores de rua aumentou, Datafolha, 4 jan 2020. Disponível em: <https://www1.folha.uol.com.br/cotidiano/2020/01/para-43-dos-brasileiros-numerode-moradores-de-rua-aumentou.shtml>. Acesso em: 9 mar. 2021.

SANTOS, M. O espaço do cidadão. São Paulo: Edusp, 2007.

SANTOS, M. Espaço e método. São Paulo: Edusp, 2008.

SLEE, T. Uberização: a nova onda do trabalho precarizado. São Paulo: Editora Elefante, 2017.

SOARES, L. T. R. Ajuste neoliberal e desajuste social na América Latina. Petrópolis: Vozes, 2001.

SOUZA, J. Os batalhadores brasileiros: nova classe média ou nova classe trabalhadora? Belo Horizonte: UFMG, 2012.

SOUZA, J. A ralé brasileira: quem é e como vive. São Paulo: Contracorrente, 2018.

SOUZA, M. L. O desafio metropolitano: um estudo sobre a problemática sócio-espacial nas metrópoles brasileiras. Rio de Janeiro: Bertrand Brasil, 2005.

SOUZA, M. L. Fobópole: o medo generalizado e a militarização da questão urbana. Rio de Janeiro: Bertrand Brasil, 2008.

THEBAUD-MONY, A.; DRUCK, G. Terceirização: a erosão dos direitos dos trabalhadores na França e no Brasil. In: DRUCK, G.; RANCO, T. (Org.). A perda da razão social do trabalho: terceirização e precarização. São Paulo: Boitempo, 2007.

VALLADARES, L. Cem anos pensando a pobreza (urbana) no Brasil. In: BOSCHI, R. R. (Org.). A construção do espaço público no Brasil. Rio de Janeiro: Rio Fundo Editora, 1994.

VASAPOLLO, L. O trabalho atípico e a precariedade. São Paulo: Expressão Popular, 2005.

SOBRE A AUTORA

Tatiana Tramontani Ramos; RAMOS, T.T. Professora do Departamento de Geografia da Universidade Federal Fluminense, em Campos dos Goytacazes (UFF-Campos). Vice-coordenadora do Programa de Pós-Graduação em Geografia da UFF-Campos. Coordenadora do Núcleo de Estudos sobre Território e Conflitos Sociais. 